\title{
Induction of Nickel Accumulation in Response to Zinc Deficiency in Arabidopsis thaliana
}

\author{
Sho Nishida ${ }^{1, \dagger}$, Aki Kato ${ }^{2}$, Chisato Tsuzuki ${ }^{2}$, Junko Yoshida ${ }^{2}$ and Takafumi Mizuno ${ }^{1, *}$ \\ 1 Graduate School of Bioresources, Mie University, Kurimamachiya-cho 1577, Tsu, Mie 514-8507, \\ Japan; E-Mail: sho3star@gmail.com \\ 2 Faculty of Bioresources, Mie University, Kurimamachiya-cho 1577, Tsu, Mie 514-8507, Japan; \\ E-Mails: aiko-pinchichance@ezweb.ne.jp (A.K.); chanchi-091122@docomo.ne.jp (C.T.); \\ 512m105@m.mie-u.ac.jp (J.Y.)
}

† Present address: Graduate School of Biosphere Science, Hiroshima University, Kagamiyama 1-7-1, Higashi-Hiroshima, Hiroshima 739-8521, Japan.

* Author to whom correspondence should be addressed; E-Mail: tmizuno@bio.mie-u.ac.jp; Tel.: +81-59-231-9607; Fax: +81-59-231-9684.

Academic Editor: Hatem Rouached

Received: 27 February 2015 / Accepted: 20 April 2015 / Published: 27 April 2015

\begin{abstract}
Excessive accumulation of nickel (Ni) can be toxic to plants. In Arabidopsis thaliana, the $\mathrm{Fe}^{2+}$ transporter, iron (Fe)-regulated transporter1 (IRT1), mediates Fe uptake and also implicates in $\mathrm{Ni}^{2+}$ uptake at roots; however, the underlying mechanism of $\mathrm{Ni}^{2+}$ uptake and accumulation remains unelucidated. In the present study, we found that zinc (Zn) deficient conditions resulted in increased accumulation of $\mathrm{Ni}$ in plants, particularly in roots, in A. thaliana. In order to elucidate the underlying mechanisms of Ni uptake correlating zinc condition, we traced ${ }^{63} \mathrm{Ni}$ isotope in response to $\mathrm{Zn}$ and found that (i) $\mathrm{Zn}$ deficiency induces short-term $\mathrm{Ni}^{2+}$ absorption and (ii) $\mathrm{Zn}^{2+}$ inhibits $\mathrm{Ni}^{2+}$ uptake, suggesting competitive uptake between $\mathrm{Ni}$ and $\mathrm{Zn}$. Furthermore, the Zrt/Irt-like protein 3 (ZIP3)-defective mutant with an elevated $\mathrm{Zn}$-deficient response exhibited higher $\mathrm{Ni}$ accumulation than the wild type, further supporting that the response to $\mathrm{Zn}$ deficiency induces $\mathrm{Ni}$ accumulation. Previously, expression profile study demonstrated that $I R T 1$ expression is not inducible by $\mathrm{Zn}$ deficiency. In the present study, we found increased $\mathrm{Ni}$ accumulation in IRT1-null mutant under $\mathrm{Zn}$ deficiency in agar culture. These suggest that $\mathrm{Zn}$ deficiency induces $\mathrm{Ni}$ accumulation in an IRTI-independen manner. The present study revealed that $\mathrm{Ni}$
\end{abstract}


accumulation is inducible in response to $\mathrm{Zn}$ deficiency, which may be attributable to a $\mathrm{Zn}$ uptake transporter induced by Zn deficiency.

Keywords: Arabidopsis thaliana; nickel; transporter; zinc

\section{Introduction}

Nickel (Ni) is known to be an essential nutrient for higher plants [1,2]; however, excessive amounts of $\mathrm{Ni}$ can be toxic [3]. In Ni-contaminated areas, agricultural crops exhibit Ni-induced impairments (e.g., chlorosis and leaf deformities), and the yields are reduced [4-6]. Thus, Ni phytotoxicity is one of the problems that limit agricultural production.

To elucidate the mechanism that underlies Ni phytotoxicity, we studied the molecular mechanism of $\mathrm{Ni}$ accumulation in plants using Arabidopsis thaliana as the model. We demonstrated that excess Ni is absorbed by the iron (Fe) uptake system in A. thaliana, which is associated with iron-regulated transporter 1 (IRT1), the primary Fe uptake transporter in roots [7]. Furthermore, we revealed that excess $\mathrm{Ni}$ accumulation induces IRT1 expression, which is associated with a disorder of $\mathrm{Fe}$ homeostasis, suggesting that $\mathrm{Ni}$ accumulation further accelerates Ni accumulation by IRT1 [8].

In our previous study, Ni accumulation was greatly decreased by defects in IRTI under Fe-deficient conditions, whereas under Fe-sufficient conditions the reduction rate fell significantly, yet excess $\mathrm{Ni}$ still accumulated in the mutants, which exhibited Ni phytotoxicity [7]. This indicates that an additional pathway participates in the mediation of $\mathrm{Ni}$ accumulation in roots. Physiological evidence indicates that $\mathrm{Ni}^{2+}$ uptake competes with the magnesium $(\mathrm{Mg})$ divalent ion in algae [9], barley [10], and spinach [11]. Further, members of the Arabidopsis MRS/MGT family of $\mathrm{Mg}^{2+}$ transporters have been shown to exhibit $\mathrm{Ni}^{2+}$ uptake activities in yeast [12,13]. These reports suggest that the $\mathrm{Mg}^{2+}$ uptake system is also a pathway for $\mathrm{Ni}^{2+}$ uptake. Furthermore, a previous study suggested that $\mathrm{Ni}^{2+}$ is absorbed by uptake systems for divalent heavy metal ions (e.g., $\mathrm{Zn}^{2+}, \mathrm{Cu}^{2+}$ ) in soybean [14]. Several studies have shown that some members of the Zrt/Irt-like protein (ZIP) family, which are the homologs of IRT1, are active in the transport of these heavy metal ions [15-17], suggesting that $\mathrm{Ni}^{2+}$ is competitively absorbed by the uptake systems of these divalent cations via ZIP transporters other than IRT1.

In the present study, we found that $\mathrm{Ni}$ accumulation increased in $A$. thaliana plants under $\mathrm{Zn}$ deficiency in hydroponics. A tracer assay revealed that the ${ }^{63} \mathrm{Ni}$ absorption activity was higher in $\mathrm{Zn}$-deficient plants than in the $\mathrm{Zn}$-sufficient plants, showing that the $\mathrm{Ni}^{2+}$ uptake activity is upregulated by $\mathrm{Zn}$ deficiency. A zip3 mutant with an elevated $\mathrm{Zn}$-deficient response exhibited increased $\mathrm{Ni}$ accumulation in roots compared with that in the wild type, possibly suggesting that the Zn-deficient response increases $\mathrm{Ni}$ accumulation. Furthermore, previous studies and our data suggest that the induction of $\mathrm{Ni}$ accumulation by $\mathrm{Zn}$ deficiency is attributable to an unknown molecular mechanism independent of IRT1. 


\section{Results}

\subsection{Ni Accumulation under Zn Deficiency in Hydroponics}

To investigate the effects of Zn deficiency on $\mathrm{Ni}$ accumulation in A. thaliana, growth rates and $\mathrm{Ni}$ accumulation were determined for 4-week old plants exposed to $25 \mu \mathrm{mol} \cdot \mathrm{L}^{-1} \mathrm{NiCl}_{2}$ under $\mathrm{Zn}$-sufficient $\left(5 \mu \mathrm{mol} \cdot \mathrm{L}^{-1}\right)$ or -deficient $\left(0 \mu \mathrm{mol} \cdot \mathrm{L}^{-1}\right)$ conditions for 7 days in a hydroponic culture. As an additional control measure, plants were grown in the $\mathrm{Zn}$-deficient conditions without $\mathrm{Ni}$ exposure. There was no statistically significant difference in growth between treatments (Figure 1A). Ni concentrations in the roots were $40 \%$ higher under the $\mathrm{Zn}$-deficient conditions than those under the $\mathrm{Zn}$-sufficient conditions (Figure 1B). A slight increase in Ni concentrations was observed in the shoots under the Zn-deficient conditions; however, Ni concentrations in whole plants were significantly higher under the $\mathrm{Zn}$-deficient conditions than under the $\mathrm{Zn}$-sufficient conditions.
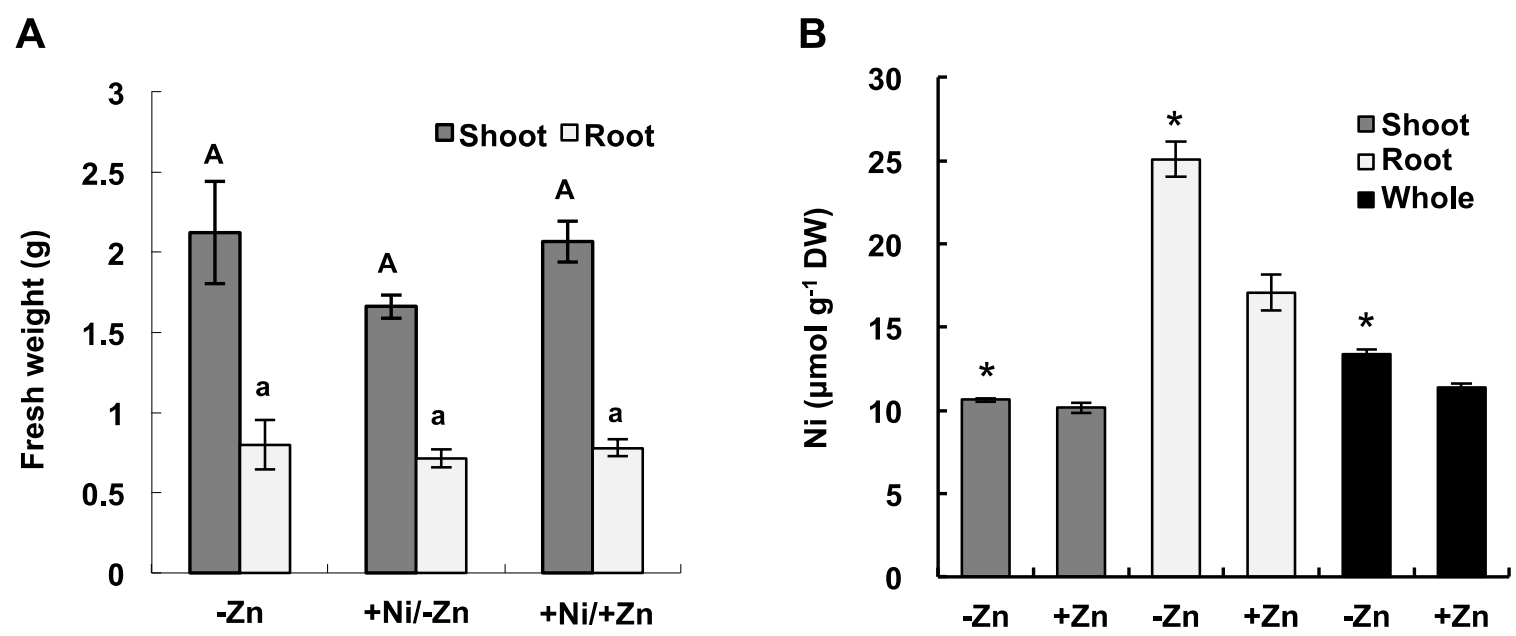

Figure 1. Ni accumulation in plants grown under Zn-sufficient or -deficient conditions. Four-week-old plants were exposed to $25 \mu \mathrm{mol} \cdot \mathrm{L}^{-1} \mathrm{NiCl} 2$ under $\mathrm{Zn}$-sufficient $\left(5 \mu \mathrm{mol} \cdot \mathrm{L}^{-1}\right.$ ) or -deficient $\left(0 \mu \mathrm{mol} \cdot \mathrm{L}^{-1}\right)$ conditions for 7 days in a hydroponic culture. (A) Fresh weight. The same letters in each series (uppercase for shoots and lowercase for roots) indicate no significant difference ( $p \geq 0.05$, Steel-Dwass test) between treatments; (B) Ni concentrations in the shoots, roots, and whole plants. Asterisks denote significant differences $(p<0.05$, Wilcoxon-Mann-Whitney test) between the Zn-sufficient and -deficient conditions for each tissue. The values represent means \pm SD based on four independent experiments.

\subsection{Short-Term ${ }^{63} \mathrm{Ni}$ Absorption in Zn-Deficient/Sufficient Plants}

$\mathrm{Ni}$ concentration in roots represents the sum of the amount of $\mathrm{Ni}$ absorbed into the cell and the amount of $\mathrm{Ni}$ adsorbed onto the cell wall. On the cell wall, metal ions bind loosely to negatively charged sites, and the metals bound to the cell wall are readily removed by washing them with solutions containing competitive cations $[11,18,19]$. The proportion of $\mathrm{Ni}^{2+}$ among the total metal ions in the hydroponic solutions used in the above experiments was $0.0738 \%$ in both the $\mathrm{Zn}$-absent and -present conditions. There was probably no difference in the amount of $\mathrm{Ni}$ fraction adsorbed in the different $\mathrm{Zn}$ conditions; therefore, we assumed that the increased $\mathrm{Ni}$ accumulation in roots under the 
Zn-deficient conditions represented the increased Ni absorption by the cells. Cataldo et al. [14] have suggested that $\mathrm{Ni}^{2+}$ and $\mathrm{Zn}^{2+}$ partially share the same uptake transporter in soybean. This could also be the case in $A$. thaliana, where $\mathrm{Ni}^{2+}$ was readily absorbed in the absence of competitive ions in the present study. Moreover, it is possible that the $\mathrm{Ni}^{2+}$ uptake activity of the roots was enhanced in response to $\mathrm{Zn}$ deficiency. To assess these possibilities, we performed a short-term $\mathrm{Ni}^{2+}$ uptake experiment using ${ }^{63} \mathrm{Ni}$-labeled $\mathrm{NiCl}_{2}\left({ }^{63} \mathrm{NiCl}_{2}\right)$ and compared difference in $\mathrm{Ni}^{2+}$ uptake activities between $\mathrm{Zn}$-deficient and -sufficient plants. One-month-old plants were grown under Zn-deficient $\left(0 \mu \mathrm{mol} \cdot \mathrm{L}^{-1}\right)$ or -sufficient $\left(5 \mu \mathrm{mol} \cdot \mathrm{L}^{-1}\right)$ conditions for 4 days in a hydroponic culture, and ${ }^{63} \mathrm{Ni}$ uptake was determined with $5 \mu \mathrm{mol} \cdot \mathrm{L}^{-1}{ }^{63} \mathrm{NiCl}_{2}$ in the presence of $\mathrm{Zn}\left(5 \mu \mathrm{mol} \cdot \mathrm{L}^{-1}\right)$ or absence of $\mathrm{Zn}$ for $1 \mathrm{~h}$. Our preliminary experiments revealed that ${ }^{63} \mathrm{Ni}$ was almost undetectable in the shoots using this assay system; therefore, Ni uptake by plants was evaluated on the basis of ${ }^{63} \mathrm{Ni}$ accumulation in the roots. To consider only the absorbed ${ }^{63} \mathrm{Ni}$, the apoplastic ${ }^{63} \mathrm{Ni}$ was removed by incubating it in a wash solution containing $5 \mathrm{mmol} \cdot \mathrm{L}^{-1} \mathrm{Ca}\left(\mathrm{NO}_{3}\right)_{2}$ and $5 \mu \mathrm{mol} \cdot \mathrm{L}^{-1}$ cold $\mathrm{NiCl}_{2}$, according to the established methods $[11,18,19]$. Statistical comparisons were made on ${ }^{63} \mathrm{Ni}$ accumulation between the $\mathrm{Zn}$-sufficient and -deficient roots in each Zn-present and -absent condition. Under the $\mathrm{Zn}$-absent condition, ${ }^{63} \mathrm{Ni}$ accumulation in the Zn-deficient roots was significantly higher (by 1.5-fold) than that in the Zn-sufficient roots (Figure 2), indicating that the ${ }^{63} \mathrm{Ni}$ absorption activity was induced in the Zn-deficient roots, as we had expected. But, there was no significant difference in ${ }^{63} \mathrm{Ni}$ accumulation between the $\mathrm{Zn}$-sufficient and -deficient roots in the Zn-present condition. The addition of Zn to Zn-present and $\mathrm{Zn}$-absent condition caused a significant decrease in $\mathrm{Ni}$ accumulation for both conditions (Wilcoxon-Mann-Whitney test, $p<0.05$ ). This is suggesting that $\mathrm{Ni}^{2+}$ uptake is competitively inhibited by $\mathrm{Zn}^{2+}$, as observed in soybean.

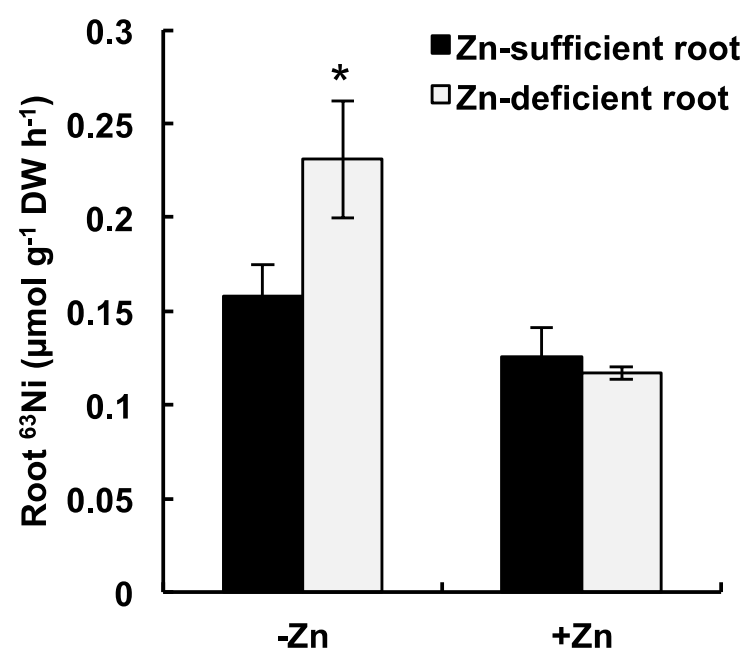

Figure 2. Short-term ${ }^{63} \mathrm{Ni}$ uptake by plants. Plants grown under $\mathrm{Zn}$-sufficient $\left(5 \mu \mathrm{mol} \cdot \mathrm{L}^{-1}\right)$ or -deficient $\left(0 \mu \mathrm{mol} \cdot \mathrm{L}^{-1}\right)$ conditions for 4 days were incubated in hydroponic solutions containing $5 \mu \mathrm{mol} \cdot \mathrm{L}^{-1}{ }^{63} \mathrm{NiCl}_{2}$ in the presence of $\mathrm{Zn}\left(5 \mu \mathrm{mol} \cdot \mathrm{L}^{-1} \mathrm{ZnCl}_{2}\right)$ or absence of $\mathrm{Zn}\left(0 \mu \mathrm{mol} \cdot \mathrm{L}^{-1}\right)$ for $1 \mathrm{~h}$. Asterisks denote significant differences $(p<0.05$, Wilcoxon-Mann-Whitney test) between the Zn-sufficient and -deficient roots, and the values represent means \pm SD based on four independent experiments. 


\subsection{Ni Accumulation in a ZIP3 Mutant}

ZIP3 is a member of the ZIP family, and it has been shown to be highly induced by Zn deficiency in the roots of $A$. thaliana $[16,20]$. It was also found that $Z I P 3$ complemented the $\mathrm{Zn}^{2+}$-uptake transporter of yeasts [15]. Therefore, it has been suggested that ZIP3 is involved in $\mathrm{Zn}$ nutrition of the roots. We obtained a T-DNA mutant zip3-1, which carries a T-DNA insertion in the second intron of ZIP3 (Figure 3A). The expression of the full length of ZIP3 was undetectable in zip3-1 (Figure 3B), confirming that this strain is defective in ZIP3 expression. Four-week-old plants of the zip3-1 mutant and wild type were grown under $\mathrm{Zn}$-sufficient conditions $\left(5 \mu \mathrm{M} \mathrm{ZnCl}_{2}\right)$ for 1 week in hydroponics, and we examined ZIP4 expression, which is a well-known indicator of Zn deficiency [21]. ZIP4 expression increased more than twofold in zip3-1 compared with that in Col-0 (Figure 3C), indicating that the Zn-deficient response was elevated in zip3-1, even under Zn-sufficient conditions. There was no significant difference in IRT1 expression between the zip3-1 mutant and the wild type (Figure 3D). Next, we exposed 4-week-old zip3-1 mutant plants and wild type plants to $25 \mu \mathrm{M} \mathrm{NiCl} 2$ under $\mathrm{Zn}$-sufficient conditions $\left(5 \mu \mathrm{M} \mathrm{ZnCl}_{2}\right)$ for 1 week and determined $\mathrm{Ni}$ accumulation in the roots. $\mathrm{Ni}$ accumulation increased by 1.5 fold in zip3-1 compared with that in the wild type (Figure $3 \mathrm{E}$ ). This result is suggesting that $\mathrm{Ni}$ accumulation can be increased in a mutant that exhibits an endogenously elevated $\mathrm{Zn}$-deficient response, which is supporting the hypothesis that $\mathrm{Ni}$ accumulation increases in plants in response to $\mathrm{Zn}$ deficiency.

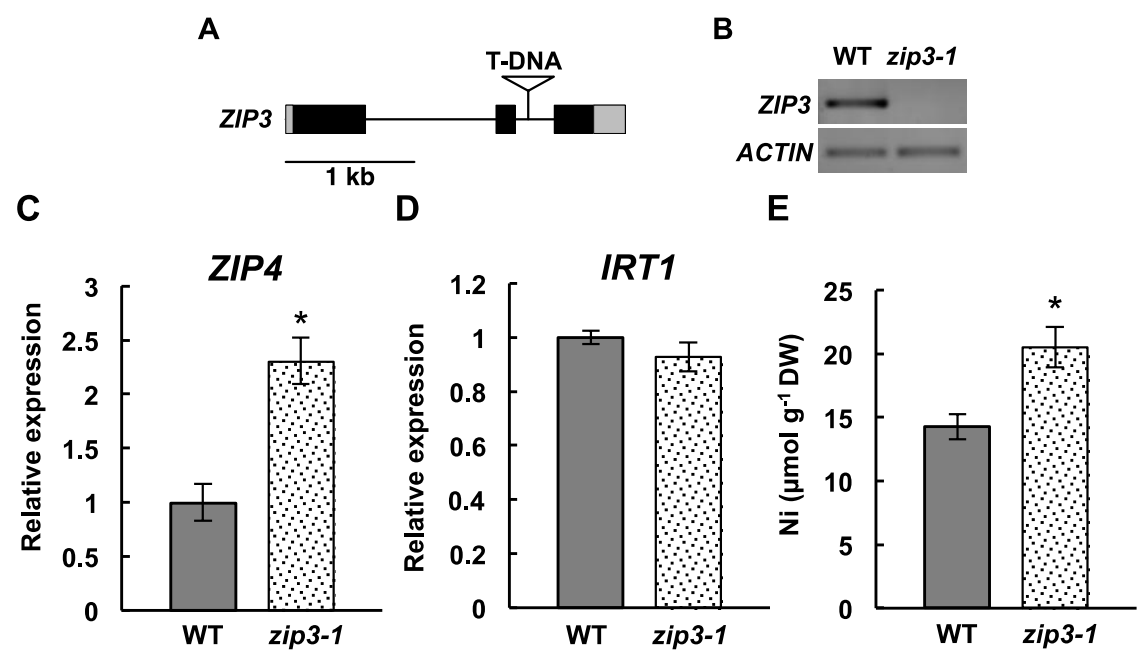

Figure 3. Ni accumulation in the Zrt/Irt-like protein 3 (ZIP3) mutant. (A) Scheme showing the T-DNA insertion site in zip3-1; (B) Semi-quantitative amplification of full-length CDS of ZIP3 in the roots of the wild type and zip3-1. The results shown were obtained after 30 cycles of amplification. Actin was amplified as an endogenous control; (C,D) Quantification of the expression levels of ZIP4, a well-known Zn-deficient response indicator and IRT1 in roots grown in $\mathrm{Zn}$-sufficient condition $\left(5 \mu \mathrm{M} \mathrm{ZnCl}_{2}\right)$ for 1 week. The expression levels relative to $E F 1 \alpha$ are shown; (E) Ni accumulation in roots. Four-week-old plants were exposed to $25 \mu \mathrm{mol} \cdot \mathrm{L}^{-1} \mathrm{NiCl}_{2}$ under $\mathrm{Zn}$-sufficient conditions $\left(5 \mu \mathrm{mol} \cdot \mathrm{L}^{-1} \mathrm{ZnCl}_{2}\right.$ ) for 1 week in hydroponic culture. The data represent means \pm SD based on three $(\mathbf{C , D})$ and four (E) independent experiments. Asterisks denote significant differences $(p<0.05$, Wilcoxon-Mann-Whitney test) between zip3-1 and the wild type. 


\subsection{Ni Accumulation in the IRT1 Mutant}

We also examined $\mathrm{Ni}$ accumulation in Zn-deficient and -sufficient conditions in an IRT1-defective mutant. We reported two independent IRT1-defective mutants in the Col-0 background [7]. But, here we used irt1-2, which has a null mutation in IRT1, to exclude the effect of IRT1 as much as possible. irt1-2 carries a T-DNA insertion in the open-reading frame of IRT1 and expresses a mutated IRTI coding for a non-functional form [7]. Because the irt1-2 plants cannot grow in the normal hydroponic culture, we needed to use an agar plate containing sucrose to maintain irt1-2 growth as described in our previous report. As a result of preliminary test with Col-0, we confirmed that $\mathrm{Zn}$ accumulations in the shoots and roots of plants grown on the Zn-deficient plate were significantly decreased compared with those of plants grown on the Zn-sufficient plate (Figure S1). In Col-0 plants, the mean Ni concentration in roots was increased by $15 \%$ in the $\mathrm{Zn}$-deficient conditions compared with that in the Zn-sufficient conditions, although not statistically significant ( $p=0.3$, Wilcoxon-Mann-Whitney test) (Figure 4), possibly suggesting that $\mathrm{Ni}$ accumulation is increased by $\mathrm{Zn}$ deficiency in agar culture. In irt1-2 plants, Ni accumulation in roots was significantly increased under the Zn-deficient conditions. These results indicate that the increased $\mathrm{Ni}$ accumulation by $\mathrm{Zn}$ deficiency is also observed in agar culture at least in irt1-2.

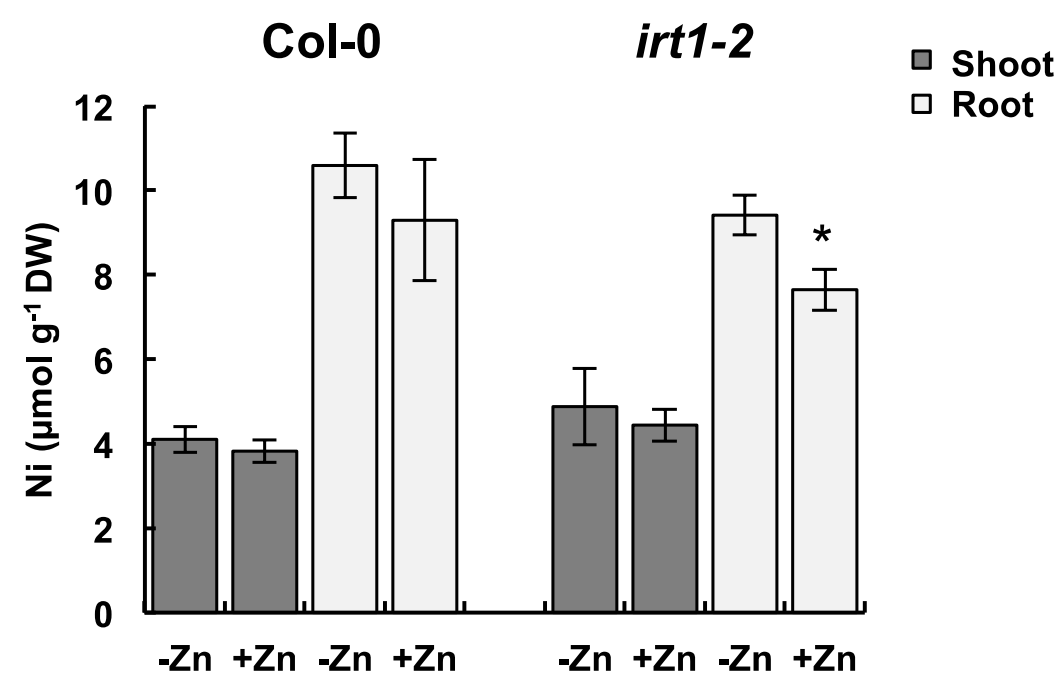

Figure 4. Ni accumulation in iron-regulated transporter1-2 (irt1-2) under Zn-sufficient and -deficient conditions. One-week-old plants were grown on MGRL plates containing $25 \mu \mathrm{mol} \cdot \mathrm{L}^{-1} \mathrm{NiCl}_{2}$ and 0 or $5 \mu \mathrm{mol} \cdot \mathrm{L}^{-1} \mathrm{ZnCl}_{2}$ for 1 week. Asterisks denote significant differences ( $p<0.05$, Wilcoxon-Mann-Whitney test) between the $\mathrm{Zn}$-sufficient and -deficient conditions. The values represent means \pm SD based on four independent experiments.

\section{Discussion}

In this study, we showed that $\mathrm{Ni}$ accumulation was increased by $\mathrm{Zn}$ deficiency in $A$. thaliana. An increased $\mathrm{Ni}$ accumulation was clearly observed in the roots, whereas the increase was quite small in the shoots. In a previous study, no marked difference was noted in $\mathrm{Ni}$ accumulation in the shoots of the irtl mutant and the wild type, although $\mathrm{Ni}$ accumulation in roots was much lower in irt1 [7]. Thus, it appears that the effect of increased or decreased $\mathrm{Ni}$ absorption in roots is not reflected by 
$\mathrm{Ni}$ accumulation in shoots. Therefore, we mainly focused on $\mathrm{Ni}$ accumulation in roots in the present study.

In a radioisotope tracer experiment, we assessed $\mathrm{Ni}^{2+}$ absorption in roots treated under $\mathrm{Zn}$-deficient and -sufficient conditions and found that ${ }^{63} \mathrm{Ni}$ absorption was higher in Zn-deficient roots, indicating that the $\mathrm{Ni}^{2+}$ absorption activity is induced in response to $\mathrm{Zn}$ deficiency in wild type plants. We also found that the zip 3 mutant, which exhibits a constitutively elevated Zn-deficient response, accumulated higher levels of $\mathrm{Ni}$ than the wild type. This observation further supports that $\mathrm{Ni}^{2+}$ absorption is inducible in response to $\mathrm{Zn}$ deficiency. In the tracer assay, we also observed that the increased ${ }^{63} \mathrm{Ni}$ absorption in Zn-deficient roots was considerably inhibited by adding $\mathrm{Zn}$ to the uptake solution, suggesting that $\mathrm{Ni}^{2+}$ can be competitively absorbed via a $\mathrm{Zn}^{2+}$ uptake pathway, which is similar to that found in soybean [14]. These findings may indicate that $\mathrm{Ni}^{2+}$ is absorbed via a $\mathrm{Zn}^{2+}$ uptake transporter induced by $\mathrm{Zn}$ deficiency in roots.

It is known that IRT1 is active in $\mathrm{Zn}^{2+}$ uptake [22,23]; however, its expression is not induced by $\mathrm{Zn}$ deficiency [16,20]. Further, the irt1 mutant exhibited an increased Ni accumulation under Zn-deficient conditions in agar culture in the present study. These are suggesting that the increased Ni accumulation caused by Zn deficiency occurs independently of IRT1. But, we note that further studies are necessary in order to conclude that $\mathrm{Zn}$-deficient induced $\mathrm{Ni}$ accumulation observed in hydroponic culture is also independent of IRT1. IRT1 expression did not increase in the zip3 mutant, and thus IRT1 was probably not the cause of the increased $\mathrm{Ni}$ accumulation in the zip3 mutant.

The findings of the present study provide considerable insights to elucidate the molecular mechanisms of Ni accumulation in plants. In A. thaliana, it has been shown that two closely related members of the basic-region leucine-zipper family of transcription factors, bZIP19 and bZIP23, are responsible for the primary responses to $\mathrm{Zn}$ deficiency and that the bzip19 bzip23 double mutant is unable to induce some genes responsive to $\mathrm{Zn}$ deficiency [21]. In the present study, Ni accumulation caused by $\mathrm{Zn}$ deficiency could have been controlled by these transcription factors. Our data also suggest that $\mathrm{Ni}^{2+}$ is competitively taken up by a $\mathrm{Zn}^{2+}$ transporter. The transporter genes that play a role in $\mathrm{Zn}^{2+}$ uptake by A. thaliana roots are uncertain; however, as previously mentioned, several studies have shown that some ZIP family genes encode $\mathrm{Zn}^{2+}$ uptake transporters, which are induced by $\mathrm{Zn}$ deficiency [17,20,21]. Therefore, it is expected that other ZIP members will also have $\mathrm{Ni}^{2+}$ transport activities. Currently, we are investigating the possible involvement of other Arabidopsis ZIP genes in $\mathrm{Ni}^{2+}$ uptake.

\section{Experimental Section}

\subsection{Analysis of Ni Accumulation in Plants Grown in Hydroponic Culture and Agar Plate Culture}

The $A$. thaliana ecotype Col-0 was cultured in a hydroponic system, as described in our previous study [7]. Four-week-old plants were irrigated with a hydroponic solution containing $25 \mu \mathrm{mol} \cdot \mathrm{L}^{-1}$ $\mathrm{NiCl}_{2}$ and 0 or $5 \mu \mathrm{mol} \cdot \mathrm{L}^{-1} \mathrm{ZnCl}_{2}$ and were cultured for 1 week. After exposure, the plants were rinsed with deionized water, and the fresh weights were determined. The plant parts were then dried at $70{ }^{\circ} \mathrm{C}$ for 3 days to determine the dry weight. We confirmed that the abundance of free $\mathrm{Ni}^{2+}$ in the hydroponic solution was $>99 \%$ of the total $\mathrm{Ni}$ in both the $\mathrm{Zn}$-sufficient and -deficient conditions using GEOCHEM-EZ [24]. 
Plants with irt1-2 (SALK_054554), which is a previously described null mutant of IRT1 in the Col-0 background [7], and the wild type were grown on MGRL-base agar plates, which comprised half-strength MGRL supplemented with 1.5\% sucrose, 1.2\% ultra-pure agar (Sigma-Aldrich Co., Tokyo, Japan), $5 \mathrm{mmol} \cdot \mathrm{L}^{-1} \mathrm{MES}$ (pH 5.5), and $50 \mu \mathrm{mol} \cdot \mathrm{L}^{-1}$ FeNa-EDTA. One-week-old seedlings were transferred to agar plates, which were supplemented with $25 \mu \mathrm{mol} \cdot \mathrm{L}^{-1} \mathrm{NiCl}_{2}$ and 0 or $5 \mu \mathrm{mol} \cdot \mathrm{L}^{-1}$ $\mathrm{ZnCl}_{2}$ and grown for 1 week. After exposure, the plants were sampled as described above.

The plant samples were digested with $\mathrm{HNO}_{3}$ and $\mathrm{H}_{2} \mathrm{O}_{2}$ in a heat block. The elemental analysis was performed using an inductively coupled plasma (ICP) atomic emission spectrometer (ICPS-7500; Shimadzu Co., Kyoto, Japan) or ICP mass spectrometer (SPQ9700; Hitachi High-Teck Science Co., Tokyo, Japan).

\subsection{Short-Term $\mathrm{Ni}^{2+}$ Uptake Assay Using ${ }^{63} \mathrm{Ni}$ Isotope}

One-month-old plants cultured under hydroponic conditions were grown in hydroponic solutions containing 0 or $5 \mu \mathrm{mol} \cdot \mathrm{L}^{-1} \mathrm{ZnCl}_{2}$ for 4 days. Next, the roots were rinsed with deionized water and gently blotted, and the plants were irrigated with a hydroponic solution containing $5 \mu \mathrm{mol} \cdot \mathrm{L}^{-1}{ }^{63} \mathrm{NiCl}_{2}$ (2.16 $\mu \mathrm{Ci} \cdot \mathrm{mL}^{-1}$, Nuclitec $\mathrm{GmbH}$, Braunschweig, Germany) with or without $5 \mu \mathrm{mol} \cdot \mathrm{L}^{-1} \mathrm{ZnCl}_{2}$, and incubated in the growth chamber under the conditions described above. After $1 \mathrm{~h}$, the plants were placed into wash solutions containing $5 \mathrm{mmol} \cdot \mathrm{L}^{-1} \mathrm{Ca}\left(\mathrm{NO}_{3}\right)_{2}$ and $5 \mu \mathrm{mol} \cdot \mathrm{L}^{-1} \mathrm{NiCl}_{2}$ for $30 \mathrm{~min}$ at room temperature. This step facilitated the desorption of ${ }^{63} \mathrm{Ni}$ ions, which were adsorbed onto the root cell walls via the equilibrium effect, as previously described $[11,18,19]$. The ${ }^{63} \mathrm{Ni}$ contents of the roots were determined using previously described procedures [7] with a liquid scintillation counter (LSC-5100; Hitachi Aloka Medical Ltd., Tokyo, Japan). The hydroponic culture conditions were the same as those described above.

\subsection{Identification of the ZIP3-Defective Mutant and Gene Expression Analysis}

The T-DNA mutant lines zip3-1 (CS870394) were acquired from the Syngenta Arabidopsis Insertion Library (SAIL) collection via the Arabidopsis Biological Resource Center (ABRC). Homozygous insertion mutants were identified using genomic polymerase chain reaction (PCR) with the following primers: 5'-TGA CTA ACA GAA CTA TAG AAG ACG CAT G-3' and 5'-CAT GCC ATT TAT TGT CGA TGA TGA CGA-3'.

The Col-0 and zip3-1 plants were grown in hydroponics for 4 weeks, as described above, and the plants were then transferred to $\mathrm{Zn}$-sufficient conditions $\left(5 \mu \mathrm{mol} \cdot \mathrm{L}^{-1} \mathrm{ZnCl}_{2}\right)$ and cultured for 1 week. Total RNA was extracted from the roots, according to the method reported by Suzuki et al. [25]. Genomic DNA in the extracts was digested with DNase I (Takara Bio Inc., Shiga, Japan), and the first-strand cDNA was synthesized from the total RNA using the PrimeScript ${ }^{\mathrm{TM}}$ RT reagent kit (Takara Bio Inc.). The cDNA was used in the following semi-quantitative and quantitative RT-PCR assays.

Amplification of the full-length coding region of ZIP3 (AT2G32270) was conducted using the above mentioned gene-specific primers and cDNA corresponding to $5 \mathrm{ng}$ of RNA. PrimerSTAR ${ }^{\circledR} \mathrm{HS}$ DNA Polymerase (Takara Bio Inc.) was used for PCR. ACTIN (AT2G37620) was also amplified as an internal control with the following primers: 5'-AAT TGG GAT GAC ATG GAG AAG ATT TGG-3' 
and 5'-TGG AGT TAT AGG TGG TTT CAT GGA TAC-3'. The PCR products on the agarose gels were detected by staining with ethidium bromide.

cDNA corresponding to $5 \mathrm{ng}$ of RNA was used for quantitative RT-PCR with SYBR Premix Ex Taq II (Takara Bio Inc.). The PCR reaction was performed with a Thermal Cycler Dice Real Time System II ${ }^{\circledR}$ (Takara Bio Inc.). For the thermal profile, instructions included in the manual provided with the PCR kit were followed. The specific primers used for ZIP4 (AT1G10970) were as follows: 5'-GGT TGT ATC CTC CAG GCT GAG T-3' and 5'-TGG TGT TGT TAC CGC GAA AA-3'. The specificities of the primers were confirmed by analyzing the dissociation curves and agarose gel electrophoresis of the PCR products. The specific primers for EFla designed by Takano et al. [26] were used.

\section{Conclusions}

In the present study, we demonstrated that $\mathrm{Zn}$ deficiency induces $\mathrm{Ni}$ absorption activity in roots and $\mathrm{Zn}^{2+}$ inhibits $\mathrm{Ni}^{2+}$ uptake. We also found $\mathrm{Ni}$ accumulation can be increased in IRT1-null mutant. Taken together, our data suggest that $\mathrm{Ni}$ is absorbed by an unknown $\mathrm{Zn}$ transporter induced by Zn deficiency.

\section{Supplementary Materials}

Supplementary materials can be found at http://www.mdpi.com/1422-0067/16/05/9420/s1.

\section{Acknowledgments}

We thank Toru Fujiwara (The University of Tokyo) for technical support in an elemental analysis with ICP-MS. We also thank Myles M. Butler and Ai Kitazumi (The University of Maine) for critically reading and Enago (www.enago.jp) for the English language review. This work was supported, in part, by a Grant-in-Aid for JSPS Fellows 09J05716 (Sho Nishida), a Grant-in-Aid for Young Research (B) 18780045 and for Scientific Research (B) 24380038 (Takafumi Mizuno) from the Japan Society for the Promotion of Science.

\section{Author Contributions}

Sho Nishida designed the experiments. Sho Nishida, Chisato Tsuzuki, Aki Kato, and Junko Yoshida performed the experiments and analyzed data. Sho Nishida and Takafumi Mizuno have contributed in writing the manuscript.

\section{Conflicts of Interest}

The authors declare no conflict of interest. 


\section{References}

1. Brown, P.H.; Welch, R.M.; Cary, E.E. Nickel: A micronutrient essential for higher plants. Plant Physiol. 1987, 85, 801-803.

2. Brown, P.H.; Welch, R.M.; Madison, J.T. Effect of nickel deficiency on soluble amino acid, and nitrogen levels in barley. Plant Soil 1990, 125, 19-27.

3. Seregin, I.V.; Kozhevnikova, A.D. Physiological role of nickel and its toxic effects on higher plants. Russ. J. Plant Physiol. 2006, 53, 257-277.

4. Temple, P.J.; Bisessar, S. Uptake and toxicity of nickel and other metals in crops grown on soil contaminated by a nickel refinery. J. Plant Nutr. 1981, 3, 473-482.

5. Frank, R.; Stonefield, K.I.; Suda, P. Impact of nickel contamination on the production of vegetables on an organic soil, Ontario, Canada, 1980-1981. Sci. Total Environ. 1982, 26, 41-65.

6. Bisessar, S. Effects of lime on nickel uptake and toxicity in celery grown on muck soil contaminated by a nickel refinery. Sci. Total Environ. 1989, 84, 83-90.

7. Nishida, S.; Tsuzuki, C.; Kato, A.; Aisu, A.; Yoshida, J.; Mizuno, T. AtIRT1, the primary iron uptake transporter in the root, mediates excess nickel accumulation in Arabidopsis thaliana. Plant Cell Physiol. 2011, 52, 1433-1442.

8. Nishida, S.; Aisu, A.; Mizuno, T. Induction of IRT1 by the nickel-induced iron-deficient response in Arabidopsis. Plant Signal. Behav. 2012, 7, 329-331.

9. Worms, I.A.; Parthasarathy, N.; Wilkinson, K.J. Ni uptake by a green alga. 1. Validation of equilibrium models for complexation effects. Environ. Sci. Technol. 2007, 41, 4258-4263.

10. Lock, K.; van Eeckhout, H.; de Schamphelaere, K.A.; Criel, P.; Janssen, C.R. Development of a biotic ligand model (BLM) predicting nickel toxicity to barley (Hordeum vulgare). Chemosphere 2007, 66, 1346-1352.

11. Degryse, F.; Shahbazi, A.; Verheyen, L.; Smolders, E. Diffusion limitations in root uptake of cadmium and zinc, but not nickel, and resulting bias in the Michaelis constant. Plant Physiol. 2012, 160, 1097-1109.

12. Li, L.; Tutone, A.F.; Drummond, R.S.; Gardner, R.C.; Luan, S. A novel family of magnesium transport genes in Arabidopsis. Plant Cell 2001, 13, 2761-2775.

13. Li, L.G.; Sokolov, L.N.; Yang, Y.H.; Li, D.P.; Ting, J.; Pandy, G.K.; Luan, S. A mitochondrial magnesium transporter functions in Arabidopsis pollen development. Mol. Plant 2008, 1, 675-685.

14. Cataldo, D.A.; Garland, T.R.; Wildung, R.E. Nickel in plants: I. Uptake kinetics using intact soybean seedlings. Plant Physiol. 1978, 62, 563-565.

15. Grotz, N.; Fox, T.; Connolly, E.; Park, W.; Guerinot, M.L.; Eide, D. Identification of a family of Zinc transporter genes from Arabidopsis that respond to zinc deficiency. Proc. Natl. Acad. Sci. USA 1998, 95, 7220-7224.

16. Wintz, H.; Fox, T.; Wu, Y.Y.; Feng, V.; Chen, W.; Chang, H.S.; Zhu, T.; Vulpe, C. Expression profiles of Arabidopsis thaliana in mineral deficiencies reveal novel transporters involved in metal homeostasis. J. Biol. Chem. 2003, 278, 47644-47653.

17. Milner, M.J.; Seamon, J.; Craft, E.; Kochian, L.V. Transport properties of members of the ZIP family in plants and their role in Zn and Mn homeostasis. J. Exp. Bot. 2013, 64, 369-381. 
18. Lasat, M.M.; Baker, A.J.; Kochian, L.V. Physiological characterization of root $\mathrm{Zn}^{2+}$ absorption and translocation to shoots in $\mathrm{Zn}$ hyperaccumulator and nonaccumulator species of Thlaspi. Plant Physiol. 1996, 112, 1715-1722.

19. Krämer, U.; Smith, R.D.; Wenzel, W.W.; Raskin, I.; Salt, D.E. The role of metal transport and tolerance in nickel hyperaccumulation by Thlaspi goesingense Hálácsy. Plant Physiol. 1997, 115, 1641-1650.

20. Van de Mortel, J.E.; Almar Villanueva, L.; Schat, H.; Kwekkeboom, J.; Coughlan, S.; Moerland, P.D.; Ver Loren van Themaat, E.; Koornneef, M.; Aarts, M.G. Large expression differences in genes for iron and zinc homeostasis, stress response, and lignin biosynthesis distinguish roots of Arabidopsis thaliana and the related metal hyperaccumulator Thlaspi caerulescens. Plant Physiol. 2006, 142, 1127-1147.

21. Assunção, A.G.; Herrero, E.; Lin, Y.F.; Huettel, B.; Talukdar, S.; Smaczniak, C.; Immink, R.G.; van Eldik, M.; Fiers, M.; Schat, H.; et al. Arabidopsis thaliana transcription factors bZIP19 and bZIP23 regulate the adaptation to zinc deficiency. Proc. Natl. Acad. Sci. USA 2010, 107, 10296-10301.

22. Korshunova, Y.O.; Eide, D.; Clark, W.G.; Guerinot, M.L.; Pakrasi, H.B. The IRT1 protein from Arabidopsis thaliana is a metal transporter with a broad substrate range. Plant Mol. Biol. 1999, 40, 37-44.

23. Vert, G.; Grotz, N.; Dédaldéchamp, F.; Gaymard, F.; Guerinot, M.L.; Briat, J.F.; Curie, C. IRT1, an Arabidopsis transporter essential for iron uptake from the soil and for plant growth. Plant Cell 2002, 14, 1223-1233.

24. Shaff, J.E.; Schultz, B.A.; Craft, E.J.; Clark, R.T.; Kochian, L.V. GEOCHEM-EZ: A chemical speciation program with greater power and flexibility. Plant Soil 2010, 330, 207-214.

25. Suzuki, Y.; Kawazu, T.; Koyama, H. Arabidopsis RNA isolation. Biotechniques 2004, 37, 542-544.

26. Takano, J.; Wada, M.; Ludewig, U.; Schaaf, G.; von Wirén, N.; Fujiwara, T. The Arabidopsis major intrinsic protein NIP5; 1 is essential for efficient boron uptake and plant development under boron limitation. Plant Cell 2006, 18, 1498-1509.

(C) 2015 by the authors; licensee MDPI, Basel, Switzerland. This article is an open access article distributed under the terms and conditions of the Creative Commons Attribution license (http://creativecommons.org/licenses/by/4.0/). 